\title{
Educação superior na sociedade pós-moderna: propagação e mercantilização do ensino na modalidade EAD no Brasil
}

Higher education in post-modern society: propagation and commercialization of education in the

\author{
EAD modality in Brazil
}

La educación superior en la sociedad post-moderna: propagación y comercialización de la educación en la modalidad EAD en Brasil

Recebido: 29/08/2021 | Revisado: 04/09/2021 | Aceito: 05/09/2021 | Publicado: 07/09/2021

Fabiano Dutra Seeger

ORCID: https://orcid.org/0000-0002-4759-9239

Universidade Franciscana, Brasil

E-mail: fabianodutra.mestrado@gmail.com

Marcos Alexandre Alves

ORCID: https://orcid.org/0000-0002-5271-0624

Universidade Franciscana, Brasil

E-mail: maralexalves@gmail.com

Taís Steffenello Ghisleni

ORCID: https://orcid.org/0000-0002-5405-9492

Universidade Franciscana, Brasil

E-mail: taisghisleni@yahoo.com.br

\begin{abstract}
Resumo
O artigo apresenta o contexto e a trajetória, bem como, uma análise acerca da problemática social da educação superior no Brasil, a partir de um estudo sobre a mercantilização e a propagação do ensino, na modalidade a distância no país e as possíveis influências na aprendizagem, decorrentes das características da sociedade pós-moderna. Para tanto, foi realizada uma pesquisa bibliográfica, em que se fez um levantamento de algumas referências teóricas publicadas por meio escrito e eletrônico, visando coletar informações e conhecimentos prévios sobre diversas posições a respeito da temática investigada.A investigação evidenciou as principais características e as mudanças mais significativas que alteraram e consolidaram a transição de um cenário educacional, que detinha uma configuração preponderantemente estatizada e presencial, para uma realidade de mercantilização do ensino, que se disseminou na sociedade pós-moderna mediante a ampliação da oferta da educação superior, sobretudo, modalidade a distância.
\end{abstract}

Palavras-chave: Ensino; Educação a distância; Mercado; Pós-modernidade.

\begin{abstract}
The article presents the context and trajectory, as well as an analysis of the social problem of higher education in Brazil, based on a study on the commodification and propagation of distance education in the country and the possible influences on learning, arising from the characteristics of the post-modern society. For that, a bibliographical research was carried out, in which a survey of some theoretical references published in written and electronic means was carried out, aiming to collect information and previous knowledge about several positions regarding the investigated theme. The investigation highlighted the main characteristics and the most significant changes that altered and consolidated the transition from an educational scenario, which had a predominantly nationalized and presential configuration, to a reality of commodification of education, which spread in postmodern society through the expansion the offer of higher education, above all, distance learning.
\end{abstract}

Keywords: Teaching; Distance education; Marketplace; Post-Modernity.

\section{Resumen}

El artículo presenta el contexto y la trayectoria, así como un análisis de la problemática social de la educación superior en Brasil, a partir de un estudio sobre la mercantilización y propagación de la educación a distancia en el país y las posibles influencias en el aprendizaje, derivadas de las características de la sociedad posmoderna. Para tanto, foi realizada uma pesquisa bibliográfica, em que se fez um levantamento de algumas referências teóricas publicadas por meio escrito e eletrônico, visando coletar informações e conhecimentos prévios sobre diversas posições a respeito da temática investigada.A investigação evidenciou as principais características e as mudanças mais significativas que alteraram e consolidaram a transição de um cenário educacional, que detinha uma configuração preponderantemente estatizada e presencial, para uma realidade de mercantilização do ensino, que se disseminou na sociedade pósmoderna mediante a ampliação da oferta da educação superior, sobretudo, modalidade la distancia.

Palabras clave: Docencia; Educación a distancia; Mercado; Posmodernidad. 


\section{Introdução}

O ensino ${ }^{1}$ superior a distância no Brasil teve origem em políticas públicas orientadas à educação no país. Tais políticas foram compostas de ações propositais do governo com vistas às demandas coletivas ligadas à educação. Desde 1996 as políticas públicas no Brasil fomentam a implementação do ensino a distância como principal medida para estender o acesso à educação superior (Castro, 2011).

A educação a distância (EAD) no Brasil teve origem na publicação da Lei de Diretrizes e Bases da Educação Nacional (LDB), de 1996 (Brasil, 1996). O objetivo da LDB/96 foi viabilizar políticas públicas que determinassem diretrizes e bases na educação nacional. Em seu conteúdo, o poder público fomentou o desenvolvimento de programas de ensino a distância, em todos os níveis, surgindo assim os primeiros licenciamentos de cursos superiores a distância, embora parecessem ainda muito incipientes. A LDB/96 apresentou no Plano Nacional de Educação (PNE) a educação como direito de todos, como fator de desenvolvimento social e econômico do país e como meio de combate à pobreza e de inclusão social. Diante de tais diretrizes, a educação a distância para o ensino superior visava viabilizar o acesso à instrução superior ao maior número possível dos jovens brasileiros. A aprovação e regulamentação da EAD no ensino superior objetivavam, já na sua origem, a expansão da oferta de vagas e um significativo aumento no número de alunos matriculados em cursos de graduação do ensino superior.

A proposta política do Brasil, em termos de propagação do ensino superior a distância, parece atingir os propósitos iniciais de suas diretrizes, já que essa modalidade de ensino tem crescido exponencialmente nos últimos anos.A referida proposta política do Brasil (de propagação do ensino superior a distância) tem demonstrado êxito ao fechamento de cada ciclo anual acadêmico. Segundo dados prestados pelo Ministério da Educação, através do Censo da Educação Superior de 2018, realizado pelo Instituto Nacional de Estudos e Pesquisas Educacionais Anísio Teixeira - INEP, o número de alunos no EAD tem crescido expressivamente na última década, em termos de alunos matriculados no ano.

Os dados divulgados pelo INEP (2018) mostram que o número de matrículas/ano no ensino superior a distância cresceu 196,6\% entre 2008 e 2018, contra um crescimento de 10,6\% no ensino superior presencial, no mesmo período. Em 2008 os alunos matriculados na modalidade EAD eram 19,8\% do total de alunos do ensino superior, enquanto os alunos que cursavam ensino superior na modalidade presencial representavam $80,2 \%$ do total. Esses índices mudaram de maneira considerável nos dez anos posteriores. Em 2018 o ensino a distância passou a representar 40\% do total de alunos matriculados, ao mesmo tempo em que a modalidade presencial reduziu para $60 \%$ do total de matrículas. Em 2018, foram registrados 3,4 milhões de alunos matriculados em instituições de ensino superior, tanto no setor público como no privado. Deste total, 1.373 milhões ( $40 \%$ do total) de alunos matricularam-se no ensino superior na categoria EAD e 2.072 milhões de alunos (60\% do total) na modalidade presencial de ensino superior (INEP, 2018).

Baseado nessa descrição do contexto atual da educação superior no Brasil percebe-se significativas mudanças nesse segmento social. Nota-se que tais mudanças colaboram, de maneira preponderante, para uma alternância na educação superior no país, que até poucos anos atrás detinha status de Educação estatizada, para uma realidade atual de "comercialização" do ensino; tratado como mercadoria. Realidade essa que parece encontrar na propagação da modalidade EAD, de ensino superior, o principal meio para consolidar essa transição, diante das atuais características da sociedade contemporânea.

A partir do contexto exposto, o presente trabalho visa apresentar uma análise acerca da problemática social da educação superior no Brasil, mediante um estudo sobre a propagação do ensino superior a distância no país e as possíveis influências nesse contexto decorrentes das características da sociedade pós-moderna. Conforme articulação teórica apresentada nos capítulos do estudo.

\footnotetext{
${ }^{1}$ Neste trabalho faz-se necessário uma breve distinção entre os termos Educação e ensino. O termo Ensino refere-se à instrução, à transmissão de informação, ao ensinamento realizado, onde o foco subsiste no conteúdo (textos, vídeos, atividades a serem realizadas, etc.), mais relacionado a um processo individualizado. Já sobre o termo Educação, faz-se referência ao modelo político, ideológico e social, de diretrizes e normas que guiam os programas e ações de ensino - a Educação como instituição.
} 


\section{Metodologia}

Foi realizada uma pesquisa bibliográfica por meio escrito e eletrônico. Entre os meses de agosto e dezembro de 2020, nas pesquisas eletrônicas, foram acessadas as bases de dados do Google Acadêmico, Google tradicional, Scielo e Lilacs, utilizando as seguintes palavras-chave em português: EAD, Educação, Mercado e Sociedade Pós-Moderna. Dos artigos relacionados a estes temas, foram selecionados cinco artigos científicos completo, disponível em plataformas virtuais, e cinco livros que tem relativa familiaridade com a proposta temática deste estudo. Coletando assim, informações e conhecimentos prévios sobre diversos posicionamentos a respeito do tema proposto, que possibilitou a elaboração articulações teóricas relacionadas ao tema investigado, conforme exposto no desenvolvimento subsequente.

Quadro 1: Estrutura da coleta metodológica.

\begin{tabular}{|c|c|c|c|c|}
\hline Bases & $\begin{array}{l}\text { Palavras- } \\
\text { chave }\end{array}$ & Publicação & Autoria & Ano \\
\hline \multirow{10}{*}{$\begin{array}{l}\text { Google } \\
\text { Acadêmico, } \\
\text { Google } \\
\text { tradicional, } \\
\text { Scielo } \\
\text { e Lilacs }\end{array}$} & \multirow{10}{*}{$\begin{array}{l}\text { EAD, } \\
\text { Educação, } \\
\text { Mercado e } \\
\text { Sociedade } \\
\text { Pós-Moderna }\end{array}$} & Censo da educação superior & Ministério da Educação & 2018 \\
\hline & & Diretrizes e base & Ministério da Educação & 1996 \\
\hline & & Livros Impressos & Bauman & $\begin{array}{l}1998,1999, \\
2001\end{array}$ \\
\hline & & Livros Impressos & Marx & 1980 \\
\hline & & Livros Impressos & Mores & 2001 \\
\hline & & Artigo & Bourdieu & 2009 \\
\hline & & Artigo & Bauman & 2009 \\
\hline & & Artigo & Castro & 2011 \\
\hline & & Artigo & Noula & 2009 \\
\hline & & Artigo & Furlan & 2018 \\
\hline
\end{tabular}

Fonte: Autores.

\section{O Mercado da Educação - Neoliberalismo e o Ensino como Mercadoria}

As concepções acerca do mercado da Educação no Brasil, além das considerações iniciais abordadas neste estudo, podem ser compreendidas na associação com o progresso do modelo socioeconômico neoliberal do país.

O Neoliberalismo associa-se ao liberalismo clássico, com influências de teorias econômicas neoclássicas, percebido como produto do liberalismo econômico tradicional. O Neoliberalismo pode ser compreendido como um pensamento vigente, uma ideologia, presente no eixo do Estado governamental. No viés político, trata-se de um conjunto de ideias políticas e econômicas capitalistas que defendem a não participação do Estado na economia, incentivando e priorizando a liberdade de comércio, visando o desenvolvimento social através do crescimento econômico do país. O modelo socioeconômico do neoliberalismo difunde intervenção mínima do governo no mercado de trabalho, bem como a política de privatização de empresas estatais e a livre circulação de capitais internacionais, com ênfase na globalização. No Brasil, observa-se de maneira mais clara a influência do pensamento neoliberal nos dois governos do presidente Fernando Henrique Cardoso, entre os anos de 1995 e 2003. A corrente neoliberal se fez presente mediante a privatização de várias empresas do Estado. O Brasil, seguindo e mesmo caminho de outros países no curso da globalização da economia, amplia o contexto social favorável para o consumismo (Morais, 2001).

O que é característico de uma sociedade neoliberal, consumista, fomentada pela globalização, é que a economia tenha fluidez, que os capitais, serviços e produtos possam fluir em escala, para o maior número de pessoas possíveis, características evidentes no pensamento neoliberal, de liberdade econômica, ordenada pelo mercado. 
A Educação no Brasil não parece ter seguido um caminho diferente dessa realidade de consumo. As universidades passam a responder as tendências neoliberais, de tratar o ensino como um subconjunto da política econômica, conforme citam Slaughter e Leslie, (2001 apud Furlan \& Goulart, 2018, p.397):

Seu pressuposto é de que o Estado neoliberal diminui os recursos introduzidos de modo direto nas universidades e faz com que as instituições busquem fontes alternativas de recursos. Essa categoria teórica enfoca a análise de práticas e estruturas universitárias que se aproximam das do mercado e aponta a lógica econômica como norteadora das práticas acadêmicas.

A LDB, citada anteriormente, também contribui com este cenário na medida em que forneceu maior autonomia para as universidades, como um dos princípios de gestão do ensino superior, permitindo a abertura de cursos sem prévia autorização do governo federal, o que favoreceu significativamente o crescimento do ensino superior privado no país (Furlan \& Goulart, 2018). Na última década no Brasil, o referido crescimento das universidades vem encontrando na modalidade EAD um vasto campo para sua manutenção (conforme se pode constatar nos índices expostos inicialmente). Diante do forte crescimento da EAD, da propagação do ensino superior a distância na sociedade, concentrando tal avanço na iniciativa privada, o governo delega as ações sobre os problemas culturais, econômicos e sociais que afetam a educação. Assim, desloca-se a educação para um eixo estritamente comercial, que tem no mercado do ensino essa materialização.

Os rumos da educação superior no Brasil, mediante a prática de políticas predominantemente econômicas, promoveram um crescimento significativo do EAD no país. O avanço deste modelo de ensino articula uma interação entre as pessoas com uma nova demanda econômica, do mercado da Educação, mediante o consumo do ensino, ou seja, do ensino como mercadoria.

Abordar o mercado da educação superior e o ensino a distância como mercadoria é retomar, e trazer a luz, a perspectiva marxista, sobre o modelo econômico proposto em sua época, devido à aparente proximidade com a atual realidade social da Educação exposta neste trabalho. O cenário sócio-histórico, que circunscreve o referido contexto da Educação na sociedade brasileira, remete aos referenciais teóricos dos modos e relações de produção do capitalismo, proposto por Marx.

Marx propõe que o processo de formação da humanidade estaria estritamente ligado as relações de produção e sociais entre seus integrantes. É a partir de Marx que se constrói uma perspectiva humana associada e originária da interação social. O modelo econômico que rege uma determinada sociedade é objeto de grande valor teórico para Marx. A maneira com que se estabelece este modelo econômico resultaria na determinação das características das relações sociais e dos modos de produção, bem como do próprio modo econômico-social vigente. A relação dos homens com os objetos, com as mercadorias, se estabelece pelo modo econômico vigente (Magalhães, 2009).

Marx (1980) retrata o modelo econômico de sua época através do modo capitalista de produção. Neste sistema, o capital é a fonte de conhecimento, principalmente para o proletariado, uma vez que alienado a lógica implícita, necessitaria de uma análise externa da realidade que está submetido, com vistas a desviar-se da ideologia oriunda da classe dominante. Dito de outra maneira, um modelo econômico predominantemente marcado pela dominação da classe burguesa. Decorrente disso surge o conceito de fetichismo da mercadoria (buscando aqui uma associação com EAD como produto) como capaz de transformar aspectos subjetivos em objetivos, isto é, coisas reais que as pessoas acreditam ter valor intrínseco. Para Marx, o fetichismo da mercadoria era o exemplo mais universal e simples pelo qual o capitalismo escondia as relações sociais. Marx observava a alienação como uma moeda, que tinha em uma das faces o fetichismo da mercadoria e do outro a reificação das pessoas, trazendo a noção de ideologia como uma ilusão socialmente necessária.

Marx trouxe a ideologia como a falsa consciência, a ilusão necessária no capitalismo, que todos os sujeitos apresentam na medida em se comportam como mercadorias (objetos) e não como sujeitos diante de objetos; mercadorias que 
passam, portanto, a comandar os próprios sujeitos. Nessa situação os sujeitos passam a obedecer aos objetos, sem perceber que, na medida em que os obedecem, passam a estar em um mundo onde são elas (as mercadorias) que passam a exercer a capacidade de seres vivos, uma vez em que é justamente a capacidade de agir que distingue o sujeito dos objetos.

Em uma de suas passagens teóricas, Marx questiona ser sintomático, que no capitalismo não mais se façam reformas nas calças (mercadorias) que se compram, mas que se tente emagrecer por diversos meios, até mesmo através de mutilação cirúrgica, para que se possa obedecer o que seria a vontade da mercadoria (calças), que se impõe na sociedade, com suas medidas imutáveis (Marx, 1980). De acordo com Marx, no âmbito da economia política, o fetichismo da mercadoria surge como um fenômeno social e psicológico onde as mercadorias aparentam ter vontade independente de seus produtores, alienando os sujeitos às imposições econômicas do sistema. Alienados de sua condição de reflexão crítica, os sujeitos aderem as imposições de consumo das mercadorias.

Talvez aqui possa se realizar uma das associações propostas neste estudo. O ensino a distância passa a se desenvolver de tal maneira que, pela ótica do sistema capitalista, pode ser relacionado com a condição de mercadoria viva. Mercadoria com "vontade própria”, fomentada pelo modelo econômico/social vigente, que se impõe sobre as pessoas e passa a determinar diversas alterações no âmbito da Educação, nas relações entre sujeitos envolvidos, na relação dos alunos com o ensino, dentre outras. Diante disto, instiga-se a pensar se o modelo de educação voltado à estimulação do pensamento crítico e a formação de cidadãos atuantes cedeu demasiadamente espaço ao modelo preponderantemente voltado ao lucro econômico, gerando ao ensino status de mercadoria, alienando alunos a condição de clientes?

Pensar o EAD como mercadoria permite observar sobre a alienação promovida nesse entrecho e as ideologias presentes no sistema econômico/social em vigor, bem como, os princípios presentes nas políticas governamentais aplicadas a Educação no Brasil. Nessa perspectiva, talvez o ensino EAD seja o estágio mais elaborado do ensino como mercadoria, com propósitos bem distintos aos modelos de ensino anteriores. Tal conjuntura propõe a reflexão sobre esses novos comandos, os novos contextos, das novas mercadorias, como o EAD. Permitindo buscar a compreensão destes novos arranjos sociais e a repercussão disto nas relações dos sujeitos com as mercadorias, no atual cenário da sociedade contemporânea.

Dito isso, a propagação do ensino superior a distância no Brasil parece ter deslocado a Educação de um modelo voltado para as políticas públicas atreladas a demandas sociais (as problemáticas sociais), centrada no desenvolvimento do pensamento crítico do aluno, para um modelo de Educação com foco no fomento econômico, voltado para o lucro. Dinâmica incentivada pelo consumo capitalista, estimulada por um novo produto, o ensino, agora vigorando como mercadoria. Desta maneira, observa-se o desenvolvimento de um modelo de educação (EAD) voltado para as demandas econômicas de geração de lucro, modelo avesso ao de uma Educação voltada a formação do indivíduo como um cidadão atuante, crítico.

A falta de desenvolvimento de meios sociais que propiciem uma Educação voltada para a formação de indivíduos críticos e atuantes produz consideráveis efeitos sociais, desestruturantes, conforme perspectivas teóricas da discussão subsequente deste trabalho, bem como, as características da sociedade contemporânea que também influenciam, de certo modo, a referida realidade.

\section{Sociedade Pós-Moderna e a Educação}

Cabe aqui ressaltar a conjunção das exposições até aqui realizadas e as transformações e características da sociedade contemporânea. Características que podem contribuir na compreensão acerca do contexto social que também favorece para a existência do fenômeno abordado neste estudo. 
A noção de uma nova sociedade, uma sociedade pós-moderna, pode ser pensada a partir da perspectiva de Zigmunt Bauman $^{2}$, isto é, de uma sociedade "líquida" que sugere para um novo paradigma que se vive na atualidade. Bauman mostra a distância e a transformação que existe entre o passado e o presente, assim, observa que outrora se acreditou numa sociedade futura melhor, de boa ordem social, porém, segundo ele, logo começou a existir uma inquietação sobre alguns desses ideais; a liberdade individual passou a correr sérios riscos mediante a imposição da visão de mundo de alguns, sobre o que seja da ordem do bem (Bauman, 1998). Aliás, os pensadores da escola de Frankfurt (Walter Benjamin, Theodor Adorno, Max Horkheimer e Herbert Marcuse), com a teoria crítica, já previam que a boa ordem incidiria sobre a liberdade individual, esta seria sua primeira vítima. Disto decorre a luta travada contrapondo a invasão da esfera privada pela pública (Jeffries, 2018)

O iluminismo com seu ideal de progresso, razão técnica/científica, com o desenvolvimento da máquina, fez recuar a religião, a moral e dotou o homem de novos valores calcados na liberdade e autonomia individual. O indivíduo mecanizado tornou-se solitário na multidão das grandes cidades, desumanizado. Essa imagem de civilização moderna industrial, como indica Santos (2004, p. 23), “assentada na produção e na máquina, iria se modificar desde os anos 50, ao rumar para a sociedade pós-industrial, mobilizada pelo consumo e pela informação".

Nessa comparação (transformação) entre o passado e o presente, Baumam (2001, p. 66) mostra que em nossos tempos, "com Deus em prolongado afastamento, a tarefa de projetar e servir à ordem cabe aos seres humanos". Os homens, deste modo, passam a viver num mundo por conta própria. De um passado recente, de uma força sólida, passamos para uma força líquida (Bauman, 2001).

Ora, se no passado, frente a uma visão normativa (fordista, a desordem e a ambivalência não eram bem-vindas numa ordem visionária), buscava-se um ordenamento, uma homogeneidade possível, uma explicação geral dos fenômenos (leis científicas) e confiava-se no vínculo entre a ação intencional dos indivíduos e a transformação coletiva da sociedade. Hoje, porém, não podemos mais pensar assim, pois, vive-se diante de uma sociedade que apresenta um cenário diverso do passado (pós-industrial, globalizada, individualista, consumista e fragmentada), enfim, uma sociedade de transformações rápidas, de instabilidades constantes.

Nesse cenário, pode-se observar que, diante da modernidade líquida, uma das características da sociedade pósmoderna, proposta por Bauman, é que existe uma versão privatizada e individualizada da modernidade, deste modo, o indivíduo acredita ser capazes de transformar primeiro a si próprio, para somente depois contribuir para uma possível mudança social. Atualmente, será ainda possível pensar os indivíduos preocupados em transformar a sociedade como um todo? Não se deve esquecer que ao tratar de pós-modernidade, de sociedades avançadas, em razão do individualismo exacerbado, fala-se em desmobilização e apatia política (Bauman, 2001).

Se atualmente, de fato, vive-se numa sociedade veloz, fragmentada, contraditória, individualista, de consumo exagerado e repleta de instabilidades, incertezas, então, as relações cotidianas não são mais estruturadas, mas sim fluídas (Bauman, 2001). Nessa sociedade é preciso ser flexível para se adaptar as novidades e incertezas do futuro. Desde essa perspectiva, evidencia-se a importância da reflexão sobre as inferências desta sociedade nas interações dos indivíduos nos segmentos sociais, tais como o seguimento da Educação. Se a transformação da sociedade trilhou o rumo de um mundo efêmero, também se concebe o segmento social da Educação, em determinada medida, nesse processo. Especificamente nas transformações ocorridas nos meios técnicos de comunicação, as novas tecnologias de informação, através de seus processos e como instrumentos de diferentes mediações, contribuíram para a formação de uma Educação fluída, da modalidade EAD, que circula, no sentido, muito mais enquanto um produto, atingindo os patamares de expansão expostos no início deste trabalho.

\footnotetext{
${ }^{2}$ Sociólogo e filósofo polonês. Bauman, autor de influência marxista, produziu inúmeras reflexões críticas sobre a sociedade contemporânea. Dentre seus livros cita-se: "Vidas desperdiçadas", “Amor líquido", "Ética pós-moderna”, "Mal-estar da pós-modernidade", "Modernidade e ambivalência".
} 
Nesse cenário, expõe-se o consumo da cultura em tempos de uma sociedade líquida, que impõe pressa e dinamismo, com pressupostos hegemônicos de exclusão dos estilos de vida, processos e produtos que não conseguirem acompanhar essas mudanças. Com novos valores que cercam os produtos culturais (Bauman, 2001). Uma sociedade que está mais preocupada em se livrar do passado do que em ter uma novidade nas mãos. Para se consumir cultura não é mais necessário que um produto sólido tenha sido produzido para isso (Bauman, 1999). Agora é possível estudar online, fazer reuniões de trabalhos virtuais, realizar download de filmes no celular etc. São produtos oriundos na nova realidade social, que emanam e se veiculam frente aos inúmeros processos os quais os indivíduos não controlam, apenas usam, consomem. Que apontam para a sociedade líquida, conforme proposta por Bauman (1998).

Consoante com o ponto de vista de Bauman (2001), a sociedade líquida é leve, carregar aparelhos muito pesados torna-se obstáculo, presenciar aulas demoradas, que envolvem deslocamentos distantes não coadunam com a necessidade de produzir, consumir e se movimentar rapidamente. A noção de tempo e espaço foi alterada. Pode-se estar na sala de casa, na frente de um computador, de um aparelho de TV, de celulares conectados na Internet e assim estar em contato com lugares e culturas distantes, trabalhando, estudando ou em minutos de lazer. O local e o global aproximaram-se virtualmente. É fato que no consumismo líquido moderno não se fala de posse, de aquisição ou de acúmulo de coisas, nem mesmo quando se relaciona ao conhecimento, e sim, usos instantâneos (Bauman, 1999).

O que muda da sociedade moderna, ("pesada”) para a pós-moderna, líquida, é a rapidez com que as transformações acontecem, assim, produzem-se novos estilos de vida, novos modos de pensar, sentir, agir e novas dinâmicas de consumo (Bauman, 1999).

Para Bauman (2009), na fase "líquida" da modernidade, o ensino e aprendizagem estão submetidos à pressão "desinstitucionalizante" e são continuamente persuadidos a renunciar à sua lealdade aos "princípios do conhecimento", valorizando ao contrário a flexibilidade. As pressões provêm seja do alto, do governo que pretende acompanhar os caprichosos e tendências do mundo econômico; seja de baixo, dos estudantes, expostos igualmente às demandas do mercado (Bauman, 2009).

Um efeito muito evidente dessas pressões está na percepção do deslocamento de ênfase do "ensino" para a "aprendizagem". Outro efeito evidente das pressões desinstitucionalizantes é a "privatização" e a "individualização" dos processos relacionados ao ensino, com a gradual substituição da relação primária professor-aluno pela relação fornecedorcliente, diante de um novo mercado, o da Educação (Bauman, 2009).

Sendo assim, na perspectiva de Bauman (2009), a Educação está cada vez mais ligada ao discurso da eficiência e da competitividade, sendo sua meta declarada comunicar aos envolvidos as virtudes da flexibilidade, da mobilidade e da fluidez. No ambiente líquido-moderno, a "incerteza produzida" é o instrumento de domínio mais importante quando a política de tornar precário, ineficiente e inseguro se torna rapidamente o núcleo da estratégia de domínio. Segundo Bourdieu (1988) essa estratégia refere-se às manobras resultantes da situação em que os sujeitos se tornam mais inseguros e vulneráveis e por isso ainda menos previsíveis e controláveis.

\section{Considerações Finais}

Diante da realização deste estudo, foi observada a relevância das diretrizes do mercado nas políticas sociais que se guiam por aspectos econômicos em detrimento de políticas direcionadas para a formação de cidadãos, assim como ocorreu no Brasil.

Em um contexto social favorável ao jogo livre das forças de mercado, o equilíbrio do poder entre mercado e planejamento da vida social, se desloca decididamente em direção ao primeiro. E essa realidade, não parece projetar uma boa visão de futuro no sentido de formar e legitimar poderes aos cidadãos, que deveria ser um dos objetivos centrais das políticas públicas, em especial as políticas voltadas para a Educação. A aquisição de tais poderes se obtém quando as pessoas adquirem 
a capacidade de controlar, ou ao menos de influir sobre as forças políticas, econômicas e sociais que poderiam incidir no curso de suas vidas. E essa possibilidade, em favor a formação dos cidadãos, não parece encontrar caminhos promissores diante das transformações e características da atual sociedade, em especial no segmento social da Educação.

\section{Referências}

Brasil (2017). Ministério da Educação. Instituto Nacional de Estudos e Pesquisas Educacionais Anísio Teixeira. Censo da Educação Superior 2018: Notas Estatísticas. http://www.inep.gov.br/superior/ censosuperior/sinopse/default.asp.

Brasil (1996). Lei № 9.394, de 20 de dezembro de1996. Diretrizes e bases da educação nacional. Diário Oficial da União da República Federativa do Brasil. <http://www.planalto. gov.br/ccivil_03/leis/19394.htm>.

Brasil (2007). Ministério da Educação. O Plano de desenvolvimento da educação: razões, princípios e programas.

Bauman, Z (2001). Modernidade líquida: Jorge Zahar.

Bauman, Z (1998). O mal-estar da pós-modernidade. Jorge Zahar.

Bauman, Z (1999). Globalização: as conseqüências humanas. Jorge Zahar.

Bauman, Z (2009). Entrevista sobre a educação. Desafios pedagógicos e modernidade líquida - São Paulo: Entrevista em Cadernos de Pesquisa, 39(137).

Bourdieu,P (1988). Contra o fogo: destina-se a servir à resistência contra a invasão neoliberal. Raisons d'Agir.

Castro, J. A (2011). Política Social no Brasil: uma análise da ampliação do escopo, escala e gasto público. Revista Brasileira de Monitoramento e Avaliação, n. 1.

Furlan, C. \& Goulart. S (2018). Capitalismo acadêmico e reformas neoliberais no ensino superior brasileiro. Caderno EBAPE. BR, 16(3).

Noula, I (2018). Pensamento Crítico e Desafios na Educação para a Cidadania Democrática. Educação \& Realidade, 43(3), 865-886.

Magalhães, F (2009). 10 lições sobre Marx. Vozes.

Marx, Karl (1980). O Capital. RJ: Civilização Brasileira.

Moraes, R (2001). Neoliberalismo: de onde vem, para onde vai? Editora Senac São Paulo. 